\title{
Position Statement: Exercise Guidelines to Increase Peak Bone Mass in Adolescents
}

\author{
Seok-Ki Min ${ }^{1}$, Taewoong Oh², Sang Hyun Kim³ ${ }^{3}$ Jinkyung $\mathrm{Cho}^{4}$, Ho Yeon Chung ${ }^{5}$, Dong-Ho Park, , Chang-Sun Kim ${ }^{7, *}$ \\ ${ }^{1}$ Department of Sport Science, Korea Institute of Sport Science, Seoul; \\ ${ }^{2}$ Department of Sport Leisure, College of Sport Sciences, Yongin University, Yongin; \\ ${ }^{3}$ Department of Sports Science, College of Natural Science, Chonbuk National University, Jeonju; \\ ${ }^{4}$ College of Sport Science, Sungkyunkwan University, Suwon; \\ ${ }^{5}$ Department of Endocrinology and Metabolism, Department of Medicine, Kyung Hee University Hospital at Gangdong, Kyung Hee \\ University School of Medicine, Seoul; \\ ${ }^{6}$ Department of Kinesiology, Inha University, Incheon; \\ ${ }^{7}$ Department of Physical Education, Dongduck Women's University, Seoul, Korea
}

\author{
Corresponding author \\ Chang-Sun Kim \\ Department of Physical Education, Dongduck \\ Women's University, 60 Hwarang-ro 13-gil, \\ Seongbuk-gu, Seoul 02748, Korea \\ Tel: +82-2-940-4507 \\ Fax: +82-2-940-4502 \\ E-mail: chang@dongduk.ac.kr \\ Dong-Ho Park \\ Department of Kinesiology, Inha University, \\ 100 Inha-ro, Michuhol-gu, Incheon 22212, \\ Korea \\ Tel: +82-32-860-8182 \\ Fax: +82-32-860-8188 \\ E-mail: dparkosu@inha.ac.kr

\section{*Dong-Ho Park and Chang-Sun Kim \\ contributed equally to this work and should \\ be considered co-corresponding authors.}

Received: November 4, 2019

Revised: November 13, 2019

Accepted: November 15, 2019

Copyright (C) 2019 The Korean Society for Bone and Mineral Research

This is an Open Access article distributed under the terms of the Creative Commons Attribution Non-Commercial License (http://creativecommons.org/licenses/by-nc/4.0/) which permits unrestricted non-commercial use, distribution, and reproduction in any medium, provided the original work is properly cited.

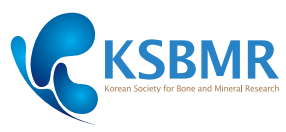

Background: An increase in bone mineral density during adolescence increases resistance to fractures in older age. The Korean Society for Bone and Mineral Research and the Korean Society of Exercise Physiology developed exercise guidelines to increase the peak bone mass (PBM) in adolescents based on evidence through a systematic review of previous research. Methods: Articles were selected using the systematic method, and the exercise guidelines were established by selecting key questions (KQs) and defining the effects of exercises based on evidence through a literature review for selecting the final exercise method. There were $9 \mathrm{KQ}$. An online search was conducted on articles published since 2000, and 93 articles were identified. Results: An increase in PBM in adolescence was effective for preventing osteoporosis and fractures in older age. Exercise programs as part of vigorous physical activity (VPA) including resistance and impact exercise at least 5 to 6 months were effective for improving PBM in adolescents. It is recommended that resistance exercise is performed 10 to 12 rep.set ${ }^{-1} 1-2$ set.region ${ }^{-1}$ and 3 days. week $^{-1}$ using the large muscles. For impact exercises such as jumping, it is recommended that the exercise is performed at least 50 jumps $\mathrm{min}^{-1}, 10 \mathrm{~min} \cdot \mathrm{day}^{-1}$ and 2 days.week ${ }^{-1}$. Conclusions: Exercise guidelines were successfully developed, and they recommend at least 5 to 6 months of VPA, which includes both resistance and impact exercises. With the development of exercise guidelines, the incidence of osteoporosis and fractures in the aging society can be reduced in the future, thus contributing to improved public health.

Key Words: Adolescent $\cdot$ Bone density $\cdot$ Exercise

\section{INTRODUCTION}

Bones are living structures that adapt to environmental needs in response to mechanical stress. There is minimum effective strain in mechanical strength; hence, bone absorption occurs when the strength is low, and bone mineral density (BMD) increases through osteogenesis when the strength is above a certain intensity.[1] Situations that provide limited mechanical loads such as flying in space or bed rests reduce the $B M D,[2]$ but sustained mechanical loads increase the $B M D,[3]$ and this 
is reflected well in the increase in BMD with regular exercise. As in the case of tennis players who report significantly higher BMD for the dominant arm compared to that for the other arm, bone reactions to mechanical strength occur locally.[4]

On the contrary, BMD decreases with age, which, in turn, increases fractures. The US Department of Health and Human Services (USDHHS) has reported that approximately $30 \%$ to $50 \%$ of women and approximately $15 \%$ to $20 \%$ of men aged 50 years will experience osteoporotic fractures during the remainder of their lives.[5] Therefore, it is important to maintain a high BMD to prevent fractures. The American College of Sports Medicine proposed 2 general strategies for increasing the resistance to fractures.[6] One is to maximize the increase in BMD during the first 30 years, and the other is to minimize the decrease in BMD after 40 years due to endocrine changes, aging, and decreased physical activity (PA). Particularly, an increase in BMD during adolescence will increase the resistance to fractures in older age. Most epidemiologic studies have also reported that increasing BMD in childhood reduces the risk of fractures due to bone loss in older age.[7] Statistical predictions also indicate that peak bone mass (PBM) achieved during puberty and early adulthood is a strong predictor of the risk of osteoporosis in older age.[8] Clark et al.[9] argue that a reduction of one standard deviation of bone mass during childhood increases the risk of fracture in adulthood by $89 \%$. Increasing the bone mass in adolescence is just as important as preventing bone loss in late adulthood in preventing fractures.[10] Lifelong bone health strategies are required to prevent osteoporosis and fractures, and these strategies have several advantages when these are performed at a young age.

The most effective strategy for increasing BMD during growth is vigorous PA (VPA) including exercise.[11] It is known that VPA is the most effective method of inducing the increase in BMD and bone strength along with structural improvement of the bones.[12] However, more than $90 \%$ of the US adolescents aged 12 to 19 years are reported to engage in inadequate $P A,[12]$ and unfortunately, the level of PA in Korean adolescents is also low with only 4.8\% exercising for approximately an hour a day.[13] Additionally, when the amount of exercise in Korean adolescents was evaluated based on the recommended amount of strenuous exercise of at least 3 times a week for at least $150 \mathrm{hr}$ a week, the proportion of those who practice this amount decreases with increasing age with $52.0 \%, 31.4 \%$, and $22.0 \%$ for elementary school, middle school, and high school students, respectively.[14] Changes in BMD during adolescence in particular are sensitive to $P A,[10]$ and a rapid decrease in the level of PA during adolescence may lower PBM levels, while a decrease in PBM level during adolescence is associated with higher incidence of osteoporosis and fractures. Therefore, to reduce the incidence of osteoporosis and fractures for the aged society in the future, efforts to increase the level of PA through exercise are needed to increase the PBM in adolescents. Although the previous studies have suggested various exercise methods to increase BMD in adolescents, it is difficult to apply them in real-life situations as the specific effects or the methods of exercises have not been clearly organized. For these reasons, the Korean Society for Bone and Mineral Research (KSBMR) and the Korean Society of Exercise Physiology (KSEP) have developed exercise guidelines to increase the PBM in adolescents based on evidence through a systematic review of previous research. The authors assume that these guidelines will be used as an exercise method to increase PBM in adolescents whether it be during physical education of middle/high school students or in the field of sports.

\section{METHODS}

These guidelines were established to suggest an intensive exercise method to improve the PBM in Korean adolescents. The KSBMR and KSEP formed a development committee (exercise committee) to establish exercise guidelines for promoting PBM in adolescents. The committee, composed of exercise physicians, on-site exercise specialists, and orthopedic surgeons, is multidisciplinary and multi-institutional. The literature was selected using systematic method as follows, and the exercise guidelines were established by selecting the key questions (KQs) and defining the effects of exercises based on evidence through the literature review for the selection of the final exercise method.

\section{Framework for developing the guidelines}

The process of developing these guidelines largely consisted of 3 phases: planning, development, and finalization. [15] Each phase was divided into 12 individual steps in total. Step 1 was planning in which the theme was selected 
(1st step), and this was followed by organizing the development committee (2nd step), reviewing previously published guidelines (3rd step), establishing development plan (4th step), and selecting the KQs (5th step). Phase 2 or the development phase consisted of evidence retrieval, evaluation, and synthesis (6th-8th steps), preparing recommendations and determining the grade for recommendations (9th step), and consensus building (10th step). The last phase, Phase 3, consisted of external review and publication (11th12th steps).

\section{Selection of Key questions}

To select the KQs to be reviewed for the establishment of exercise guidelines, an exercise committee composed of 6 members in total reviewed the position statement developed in the USA,[6] Canada,[16] and Australia [17] and reviewed papers on PA and bone health of children and adolescents published by the Society of Health and Physical Educators America.[18] Moreover, the PA Guidelines for Americans (2nd edition) published by the US Centers for Disease Control and Prevention was referenced.[19] The exercise committee subsequently selected the 12 most relevant KQs, taking into account the domestic situation and clinical significance, and finally selected the list of $9 \mathrm{KQs}$ (Table 1). The exercise method in the KQ included frequency, intensity, time, and type (FITT).

Table 1. Key questions for determining exercise guidelines

\begin{tabular}{ll}
\hline No. & \\
\hline K01 & Questions \\
K02 & Are physical activities effective for improving BMD in adolescence? \\
K03 & What is the effective way of applying physical activities to increase PBM in adolescence? \\
K04 & Are aerobic endurance exercises effective for improving BMD in adolescence? \\
K05 & How can aerobic endurance exercises be effectively applied to increase PBM in adolescence? \\
K06 & Is resistance exercise an effective strategy for improving BMD in adolescents? \\
K07 & Which type of resistance exercise can help adolescents to improve PBM? \\
K08 & Is impact (plyometric) exercise effective for improving BMD in adolescence? \\
K09 & How can impact (plyometric) exercises be applied to be effective in increasing PBM in adolescents? \\
\hline
\end{tabular}

$\mathrm{KQ}$, key question; PBM, peak bone mass; BMD, bone mineral density.

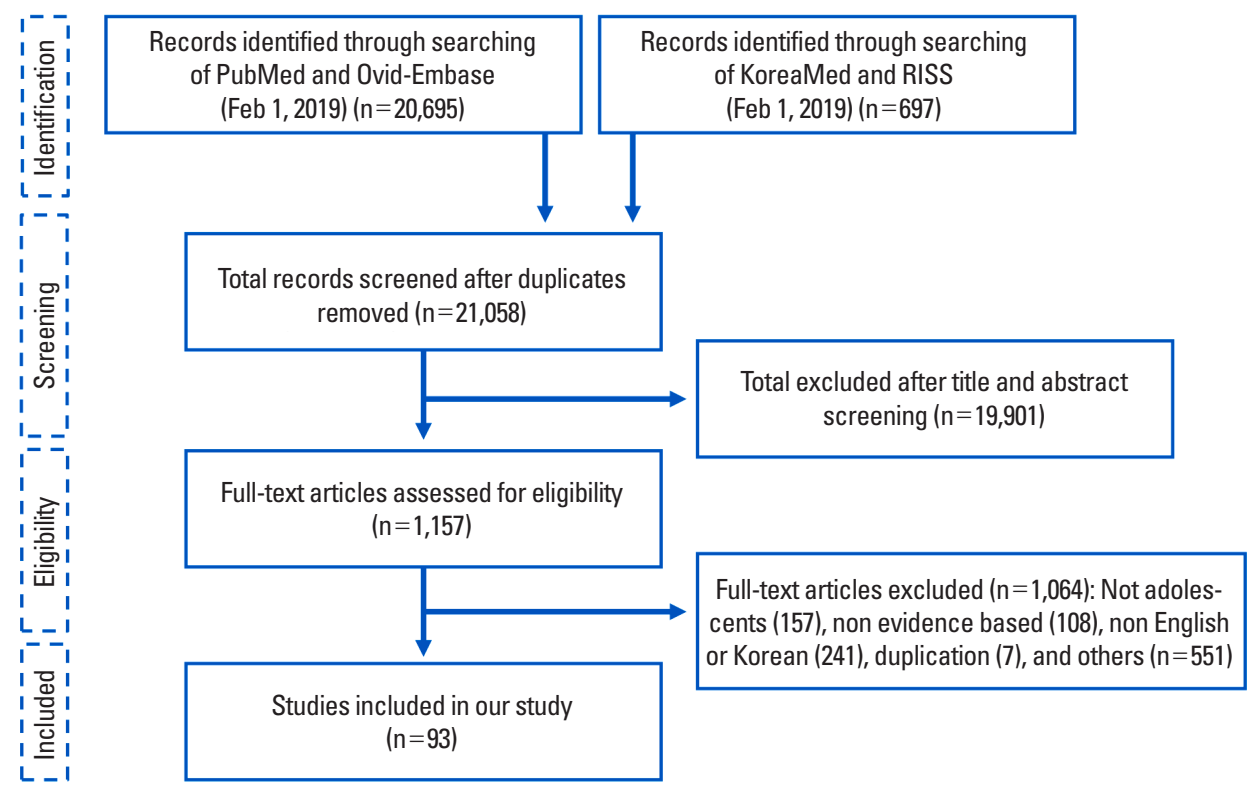

Fig. 1. Flowchart of the systematic search of literature and selection process for the development of guideline for adolescents. 


\section{Literature search}

The exercise committee conducted a systematic literature search by utilizing databases such as the PubMed of the US National Library of Medicine, Embase of Elsevier, KoreaMed of the Korean Association of Medical Journal Editors, and the Research Information Sharing Service of the Korea Education and Research Information Service. The keywords for the literature search were as follows: (aerobic $O R$ endurance $O R$ resistance $O R$ power $O R$ plyometric $O R$ exercises OR "physical activities") AND (Bone OR BMD OR "bone metabolism") AND adolescents. In the review stage, the Population, Intervention, Comparison, Outcomes, Timing, and Setting (PICOTS) framework was used to determine the scope of the literature for the systematic review.[20] The online search was conducted on articles published since 2000, and duplicate studies used the program EndNote (Clarivate Analytics, Philadelphia, PA, USA) to finally yield 21,058 relevant articles without duplicates. The results were further narrowed down to 1,157 most relevant papers, and 93 of them were finally selected (Fig. 1). The papers included in the final selection were experimental papers with clear PICOTS including systematic review, which provided evidence-based conclusions about KQ selected by the exercise committee.

\section{Final selection and preparation procedure of the guidelines}

After reviewing the evidence for each $\mathrm{KQ}$ through the literature review of the final selected papers, the exercise committee summarized the contents of the major research as a response to the $K Q$. If evidence was insufficient or clinical interpretation was required as a response to each $\mathrm{KQ}$, the decision was made through a discussion among the committee members. The strength of evidence was divided into 5 levels (Table 2). The committee subsequently gathered the comments of all committee members and finalized the final recommendation. In this process, the acceptability and applicability of the final guidelines' recommendations were evaluated, and the grade of recommendation was presented in consideration of the level of evidence, effects of exercise, and satisfaction in subjects. The grade of recommendation was determined according to the consensus principle of $80 \%$ or more with the motion committee's agreement (Table 3).

\section{RESULTS}

\section{KQ1: Is the increase in PBM in adolescence effective in preventing osteoporosis and fractures in elderly people?}

Bone mineral contents (BMCs) accumulate relatively slowly throughout childhood, but bone mineral accumulation rapidly reaches a maximum level immediately after puberty begins and upon reaching the maximum height with rapid increase in height. In European adolescents, the maximum BMD accumulation is observed at age 12.5 \pm

Table 2. The level of evidence in the literature research

\begin{tabular}{lll}
\hline Level & Expression & \multicolumn{1}{c}{ Type of evidence } \\
\hline I & High & Confirmatory study will not likely to change the results presented. \\
III & Moderate & Confirmatory study may change the results presented by research. \\
IV & Low & Conducting confirmatory study is highly likely to change the results presented. \\
EC & Very low & Claim is significantly uncertain. \\
& Expert consensus & Expert consensus (evidence accepted by the exercise committee on the basis of clear scientific analy- \\
\end{tabular}

Table 3. The grade of recommendations to exercise guideline

\begin{tabular}{lll}
\hline Grade & \multicolumn{1}{c}{ Expression } & \multicolumn{1}{c}{ Type of recommendations } \\
\hline A & Recommended & Recommended because it is sufficiently effective based on evidence. \\
B & Conditionally recommended & $\begin{array}{r}\text { The evidence for effectiveness is relatively inadequate, so it is recommended that it be selectively } \\
\text { given or given to a specific individual at the discretion of the experts. }\end{array}$ \\
C & Not recommended & Not recommended because it is insufficiently effective based on evidence. \\
D & No recommendation & $\begin{array}{l}\text { The recommendation itself is insignificant as there is no evidence for its effectiveness, and additional } \\
\text { research is required. }\end{array}$ \\
\hline
\end{tabular}


0.90 years for girls and $14.1 \pm 0.95$ years for boys.[21] During the 4 years while the bone accumulation reaches the maximum level (age 8.5 years for girls, 10.1 years for boys), $39 \%$ of the total body bone minerals are acquired, and 4 years after reaching the peak (age 16.5 years for girls, 18.1 years for boys), $95 \%$ of adult bone mass is achieved.[22] Therefore, optimizing the maximum bone minerals during this period of rapid accumulation may be effective in preventing osteoporosis and fractures in older age. However, to reach this conclusion, the assumption that young adults will lose bone mass at the same rate during the same period after PBM is achieved should be established. Fortunately, it is widely accepted that higher level of PBM achieved during young adulthood may delay the onset of fractures in older age as it may take longer for the same amount of bone loss to occur compared to a lower level of PBM. Additionally, although the PBM in female BMD varies from site to site (between ages 33 and 40 years for BMD in the lumbar spine, between ages 16 and 19 years for BMD in the hips),[23] early adolescence is the period during which bone reaction to PA is most active,[24] and the increase in PBM during this period may be effective in preventing osteoporosis and fractures in older age. In a study comparing male elite soccer players with a mean age of 69 (between ages 53-93 years) years to the control group (age 70 years, $n=$ 1,368 ), it was found that the incidence of fragility fracture in the proximal humerus, distal radius, vertebra, pelvis, hip, or tibial condyle were lower in male elite soccer players than that of the control group.[25] Berger et al.[23] found that hip BMC was $8 \%$ to $10 \%$ higher in young adults (aged 23-30 years) who engaged in VPA between ages 8 and 15 years compared to those who did not. These studies suggest the potential long-term benefits of PA in childhood on the risk of fractures in adulthood or older age. Most studies convincingly demonstrate that engaging in a high level of PA is associated with a greater bone mass gain compared to the less active group.[26] Therefore, it can be concluded that the increase in PBM in adolescence is effective in preventing osteoporosis and fractures in older age.

\section{KQ2: Is PA effective for improving BMD in adolescence?}

Bone loading during adolescence and young adulthood were significant, positive predictors of BMD of the whole body, total hip, and lumbar spine, adjusting for lean body mass and/or age.[26] PA in early and middle adolescence was positively associated with both lumbar spine and femoral neck BMD in early adulthood.[27] Frequent habitual PA in adolescence was, with the exception of cortical density, associated with greater bone size, mineral content and strength at the weight-bearing tibia in adulthood. However, PA in children and adolescents was not consistently associated with the risk of low-energy fractures later in life. [28] PA during adolescence and adulthood is recommended as a strategy for maintaining life-long skeletal health and reducing fracture risk.[29] Adolescent PA will have positive implications on bone structure and strength in young adulthood.[30] Bone benefits, especially in cortical bone size, mineral content, and strength, seemed to persist into young adulthood, even after accounting for young adult PA.[31] Thus, the physical activities are effective in improving the BMD of adolescence.

\section{KQ3: How can PA be effectively applied to increase PBM in adolescence}

VPA has been proven to promote osteogenesis in adolescents. VPA may be the most effective activity intensity to improve BMD of femoral neck and content of adolescent boys, with greater benefits if VPA bout was 15 consecutive min.[32] The beneficial effect of high impact PA on bone, applies to the average child and those genetically predisposed to lower adult BMD and lumbar spine BMD of adolescence and young adulthood, especially men who continuously participated in a high-impact PA had greater hip and lumbar spine BMD.[26] Weight-bearing loading that includes jumps seems to be the essential osteogenic stimulus.[33] Sufficiently active can improve leg and whole body BMD.[34] Thus, it is considered that the vigorous, high impact, weight-bearing loading that includes jumps are effective in order to improve PBM in adolescence (Table 4).

\section{KQ4: Are aerobic endurance exercises effective for improving BMD in adolescence?}

Aerobic endurance exercises are low-intensity, long-term exercises that use lipids in the body as the main fuel and are often used for weight management through body fat reduction. The common types of aerobic endurance exercises are running, walking, swimming, and cycling. These aerobic endurance exercises have been reported to have both negative and positive effects on improving BMD in 
Table 4. Physical activity studies in adolescents

\begin{tabular}{|c|c|c|c|c|c|}
\hline References & Study design & Participants/Age & Exercise details (FITT) & PA measures & Main findings \\
\hline $\begin{array}{l}\text { Marin-Puyalto } \\
\text { et al.[32] }\end{array}$ & $\begin{array}{l}\text { Cross-sectional } \\
\text { study }\end{array}$ & $\begin{array}{l}180 \text { healthy male } \\
\text { adolescents/ } \\
11-13 \text { years }\end{array}$ & $\begin{array}{l}\text { A: sedentary } \leq 100 \text { counts } / \text { min, B: light }>100 \text { counts/ } \\
\text { min, C: moderate } \geq 2,296 \text { counts } / \text { min, } \\
\text { D: vigorous } \geq 4,012 \text { counts } / \text { min }\end{array}$ & $\begin{array}{c}\text { PA } \\
\text { (accelerometer) }\end{array}$ & $\begin{array}{c}\text { FN BMC, FN } \\
\text { BMD: } C, D>A, B\end{array}$ \\
\hline $\begin{array}{l}\text { Nordström } \\
\text { et al.[33] }\end{array}$ & $\begin{array}{l}\text { Cross-sectional } \\
\text { study }\end{array}$ & $\begin{array}{c}64 \text { adolescent boys/ } \\
16.9 \pm 0.3 \text { years }\end{array}$ & $\begin{array}{c}\text { A: CON-physical exercise level of } 1.4 \pm 1.4 \mathrm{hr} / \text { week or } \\
\text { less, B: ice hockey players, the average training was } \\
8.5 \pm 2.2 \mathrm{hr} / \text { week, C: badminton players, the average } \\
\text { training was } 5.2 \pm 1.9 \mathrm{hr} / \text { week }\end{array}$ & $\begin{array}{c}\mathrm{PA} \\
\text { (questionnaire) }\end{array}$ & $\begin{array}{c}\text { PF BMD, DF } \\
\text { BMD: C >A, B }\end{array}$ \\
\hline Diniz et al.[34] & $\begin{array}{l}\text { Cross-sectional } \\
\text { study }\end{array}$ & $\begin{array}{l}173 \text { adolescents/ } \\
11.68 \pm 1.44 \text { years }\end{array}$ & A: inactive, B: moderately active, $\mathrm{C}$ : sufficiently active & $\begin{array}{c}\text { PA } \\
\text { (questionnaire) }\end{array}$ & $\begin{array}{l}\text { WB BMD, leg } \\
\text { BMD: C>A }\end{array}$ \\
\hline
\end{tabular}

FITT, frequency, intensity, time, and type; PA, physical activity; CON, control; FN, femoral neck; BMC, bone mineral content; BMD, bone mineral density; WB, whole body; PF, proximal femur; DF, distal femur.

adolescence. According to a study by Eliakim et al.[35] conducted in 38 male adolescents, aerobic- or endurance-type training such as running, aerobic dance, and basketball performed $2 \mathrm{hr}$ a day 5 days a week for 5 weeks increased osteogenic markers including osteocalcin, bone-specific alkaline phosphatase, and osteopontin and decreased bone absorption marker including amino-terminal collagen crosslinks. Additionally, in a study by Im [36], a 12-week track and field exercise program in female adolescents showed improvement in lumbar and femoral BMD. Furthermore, a study comparing BMD in different types of youth athletes (running, walking, cycling, triathlon, soccer) also showed statistically significant results in runners [1] and softball [37] and soccer [38] players. Hence, weight-bearing exercise programs as part of aerobic endurance exercises such as running or track and field are effective for improving $\mathrm{BMD}$ in adolescence.

However, when the correlation between running distance and lumbar BMD in endurance runners aged 18 to 44 years was analyzed, a significant negative correlation was found, [39] and these results support the findings of a study that there is a risk of fractures (BMD deterioration) associated with running more than $10 \mathrm{~km}$ per week regardless of age, suggesting that running distance must be controlled.[40] Furthermore, a study examining BMD in female high school students based on the type of sports found a lower BMD in long-distance runners than in taekwondo, judo, and weightlifting athletes.[41] These results suggest that the choice of exercise type and the control of exercise intensity will play important roles in promoting BMD in adolescents participating in aerobic endurance exercises. Swimmers (aged 10-19 years) who participated in swimming, one of the aerobic endurance exercises, were found to have a lower
BMD compared to the general control group.[42] Bellew and Gehrig [43] also compared the BMD among swimmers, weightlifters, and soccer players and found that the areal BMD in swimmers was significantly lower than that in soccer players, which was significantly lower in swimmers than in soccer players in a comparison conducted by the World Health Organization in adult females. As shown, non-weightbearing sports such as swimming or cycling and excessive long-distance exercise are likely to have negative effects on BMD improvement.

\section{KQ5: How can aerobic endurance exercises be effectively applied to increase PBM in adolescence?}

Previous research conducted to date mostly includes articles related to BMD comparison among adolescent athletes by type of sports and is limited in presenting a clear FITT, but the summary of the previous studies is shown in Table 5. Aerobic endurance-type training performed $2 \mathrm{hr}$ a day 5 times a week for 5 weeks results in an increase in osteogenic markers and a decrease in bone absorption markers,[35] while performing track and field exercise program for 60 min a day 4 times a week for 12 weeks with self-perceived intensity of 11 to 15 has been shown to be effective for improving $B M D,[36]$ suggesting that performing aerobic endurance exercise for at least 60 min a day 4 times a week for at least 5 weeks is effective in improving BMD. In addition to the quantitative increase in exercise, combined exercise in which aerobic and resistance exercises are simultaneously performed [44] is also effective; in a study conducted in female university students, positive effects were shown on BMD in both the jogging and weight training groups.[45] However, particular attention needs to be 
Table 5. Aerobic endurance exercise training studies in adolescents

\begin{tabular}{|c|c|c|c|c|c|}
\hline References & Study design & Participants/Age & Exercise type & Exercise details (FITT) & Main findings \\
\hline $\begin{array}{l}\text { Duncan } \\
\text { et al.[1] }\end{array}$ & $\begin{array}{l}\text { Cross- sec- } \\
\text { tional study }\end{array}$ & $\begin{array}{l}75 \text { female adoles- } \\
\text { cents } 15-18 \text { years }\end{array}$ & $\begin{array}{l}\text { A: swimming, B: cyclists, C: } \\
\text { running, D: triathletes, E: CON }\end{array}$ & $\begin{array}{l}\text { A-D: at least } 8 \mathrm{hr} / \text { week, } \\
\text { E: less than } 2 \mathrm{hr} / \text { week }\end{array}$ & $\begin{array}{c}\text { WB, FN BMD: C>A, E; L BMD: } \\
\text { C>A; leg BMD: C>A, B, E }\end{array}$ \\
\hline $\begin{array}{l}\text { Eliakim } \\
\text { et al.[35] }\end{array}$ & INT & $\begin{array}{l}38 \text { male adoles- } \\
\text { cents/16.0 } 0.7 \text { years }\end{array}$ & $\begin{array}{l}\text { AT (running, aerobic dance, } \\
\text { basketball, etc.) }\end{array}$ & $\begin{array}{c}\text { Total } 5 \text { weeks, } 2 \mathrm{hr} / \text { day, } \\
5 \text { days/week; } A \text { : CON }(n=18) \text {, } \\
\text { B: } E X(n=20)\end{array}$ & $\begin{array}{l}\text { Bone formation marker (osteo- } \\
\text { calcin, BSAP, PICP): } B>A \text {; bone } \\
\text { resorption marker (NTX): } B<A\end{array}$ \\
\hline $\operatorname{Im}[36]$ & INT & $\begin{array}{c}20 \text { female adoles- } \\
\text { cents/13.2 } \pm 0.79 \text { years }\end{array}$ & $\begin{array}{l}\text { Athletic exercise program } \\
\text { (walking and jogging, static } \\
\text { and dynamic stretching, } \\
\text { ladder \& mini hurdle) }\end{array}$ & $\begin{array}{l}\text { Total } 12 \text { weeks, } 60 \text { min/day, } \\
4 \text { days a week, } 1-4 \text { week: RPE } \\
\text { 11-15, } 5-12 \text { week: RPE } 13-15 ; \\
\text { A: CON }(n=10), \text { B: EX }(n=10)\end{array}$ & $\begin{array}{l}\text { L1, L4, left FN, left total femoral: } \\
\qquad B>A\end{array}$ \\
\hline $\begin{array}{l}\text { Okano } \\
\text { et al.[37] }\end{array}$ & INT & $\begin{array}{l}52 \text { female adoles- } \\
\text { cents } / 16-17 \text { years }\end{array}$ & $\begin{array}{l}\text { A: running, B: softball, C: no } \\
\text { exercise during } 18 \text { months, } \\
\text { D: no exercise } 5 \text { years }\end{array}$ & $\begin{array}{l}\text { Total } 4-5 \text { years, running and } \\
\text { circuit training } 3 \mathrm{hr} / \text { day }\end{array}$ & $\begin{array}{l}\text { L, FN, TR BMD: B >C, D; } \\
\text { TR BMD: } A>C, D\end{array}$ \\
\hline
\end{tabular}

FITT, frequency, intensity, time, and type; INT, intervention; CON, control; AT, aerobic training; EX, exercise; RPE, rating of perceived exertion; WB, whole body; FN, femoral neck; BMD, bone mineral density; L, lumbar; BSAP, bone-specific alkaline phosphatase; PICP, C-terminal procollagen peptide; NTX, Nterminal telopeptide.

paid for the nutritional and medical status for athletes engaged in non-weight-bearing sports such as swimming, cycling, and endurance running as they are more like to have a lower BMD than other athletes.

\section{KQ6: Is resistance training effective strategy for improving BMD in adolescents?}

Several studies have shown that adequate intensity, volume, and duration of resistance training can improve physical fitness, such as muscle strength, as well as physical growth and development during adolescence.[46] However, until the 1980s, youth resistance exercise was not recommended because it could predispose individuals to a high risk of musculoskeletal injuries.[46] Thus, the US Consumer Product Safety Commission's National Electronic Injury Surveillance System (NEISS) investigated the association between resistance training and injury and concluded that resistance training-induced injuries were not associated with specific activities and/or devices.[47] Resistance training performed in adolescents is known to be associated with a mild-tomoderate risk of musculoskeletal injuries as is observed with most physical activities; however, this risk is not greater than that associated with several other sports and physical activities that involve youth participation.[46] Therefore, as shown by studies presented in Table 6 , resistance training aimed at improving the BMD appears to be an effective strategy in adolescents. The intensity of resistance training required to improve BMD in adolescents has not been conclusively defined by these studies; however, moderateto-high intensity exercise was shown to be effective.[48-
51] With regard to the volume of resistance training, it was shown to be dependent on the type of resistance training performed. However, for conventional programs involving a combination of free weights and machines, 90 to 180 min of exercise per week were deemed effective. Notably, Weeks et al.[52] reported that 90 to $135 \mathrm{~min}$ of resistance exercise per week was ineffective and therefore, at least 180 min of resistance exercise per week will be required to achieve the desired effects. The duration of resistance training ranged from 12 weeks,[48] 6 to 12 months,[44,50,53] and periods $>12$ months $[43,49,51,54]$ and was effective in all periods. Therefore, although there may be slight differences in the program, depending on the intensity and volume of the exercise, even a short period of 3 months of resistance training can effectively improve the BMD in adolescents if the intensity and volume of the exercise are suitably adjusted.

\section{KQ7: How can resistance training be effectively applied to increase PBM in adolescents?}

Bone mass that demonstrates a peak during childhood and adolescence tends to continuously decline in adulthood.[40] Therefore, it is essential to improve bone strength in adolescents by enhancing PBM to lower the risk of osteoporosis and fragility fractures in adulthood. Calcium intake and weight-bearing PA are important factors associated with PBM; however, weight-bearing PA is considered more beneficial in accomplishing the PBM.[55] Specifically, high-impact jumping or resistance training is more effective in improving PBM.[6] However, an improper form and 
Table 6. Resistance training studies in adolescents

\begin{tabular}{|c|c|c|c|c|c|}
\hline References & Study design & Participants/Age & Exercise type & Exercise details (FITT) & Main findings \\
\hline $\begin{array}{l}\text { Bellew and } \\
\text { Gehrig [43] }\end{array}$ & $\begin{array}{l}\text { Cross-sec- } \\
\text { tional study }\end{array}$ & $\begin{array}{l}64 \text { female } \\
\text { athletes/ } \\
10-17 \text { years }\end{array}$ & $\begin{array}{l}\text { A: swimming, B: soccer, } \\
\text { C: weight lifting }\end{array}$ & $\begin{array}{c}\text { A: } 9.2 \pm 4.9 \mathrm{hr} / \text { week, } 11.9 \pm 0.46 \text { month/ } \\
\text { year for } 5.1 \pm 2.4 \text { year; B: } 9.7 \pm 5.0 \mathrm{hr} / \\
\text { week, } 10.9 \pm 0.31 \text { month/year for } 5.2 \pm \\
2.5 \text { year; C: } 9.8 \pm 4.0 \mathrm{hr} / \text { week, } 11.6 \pm 0.74 \\
\text { month/year for } 4.9 \pm 1.8 \text { year at least } \\
5 \mathrm{hr} / \text { week, minimum of } 10 \text { month/year }\end{array}$ & 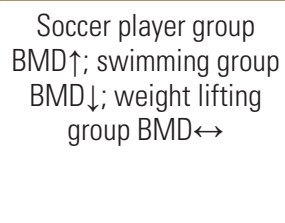 \\
\hline Campos et al.[44] & INT & $\begin{array}{l}34 \text { obese boy and } \\
\text { girl/15-19 years }\end{array}$ & AT (treadmill)+RT & $\begin{array}{c}\text { Total } 1 \text { year, } 30 \text { min AT+30 min RT, } \\
3 \text { days/week }\end{array}$ & BMC: $A<B$ \\
\hline Volek et al.[48] & INT & $\begin{array}{c}28 \text { boys } / 14.7 \pm 1.7 \\
\text { year }\end{array}$ & $\begin{array}{l}\text { A: RT+milk, B: RT+juice, } \\
\text { RT: combination of free } \\
\text { weights and machines }\end{array}$ & $\begin{array}{c}\text { Total } 12 \text { week, } 1 \mathrm{hr} / \text { day, } 3 \text { days/week, } \\
\text { increase intensity with concomitant } \\
\text { decreasing volume }\end{array}$ & $\begin{array}{l}\text { WB BMD: } A>B ; B M C \\
\text { and BMD: pre< }<\text { post in } \\
\text { all group }\end{array}$ \\
\hline Nichols et al.[49] & INT & $\begin{array}{c}67 \text { female } \\
\text { adolescents/ } \\
5.9 \pm 0.1 \text { years }\end{array}$ & $\begin{array}{l}15 \text { different exercises } \\
\text { (combination of both free } \\
\text { weights and machines) }\end{array}$ & $\begin{array}{c}\text { Total } 15 \text { months, } 30-45 \text { min a day, } \\
3 \text { times/week; exercise program: } \\
\text { 1-2 weeks (one set of } 12-14 \text { repetitions), } \\
\text { after } 2 \text { weeks ( } 9-10 \text { per set), } 2 \text { set, after } \\
10 \text { weeks ( } 9-10 \text { per set, } 3 \text { set) }\end{array}$ & $\begin{array}{l}\text { FN BMD: A>B; LS and } \\
\text { WB BMD: NS }\end{array}$ \\
\hline $\begin{array}{r}\text { Bernardoni } \\
\text { et al.[50] }\end{array}$ & INT & $\begin{array}{l}44 \text { female ado- } \\
\text { lescents (Tanner } \\
\text { breast II [T2] and III } \\
\text { [T3])/11-12 years }\end{array}$ & $\begin{array}{l}\text { Floor and resistance exercise } \\
\text { (utilizing body weight, } \\
\text { handheld weights, and } \\
\text { resistance bands) }\end{array}$ & $\begin{array}{l}\text { Total } 7 \text { months, circuits for } 8-12 \text { min, } \\
\text { 2-3 times/week, gradually increased in } \\
\text { 2-3 week, preclude the completion of an } \\
\text { additional repetition at the allotted time }\end{array}$ & LS BMD for T3个 \\
\hline Koşar [51] & $\begin{array}{l}\text { Cross-sec- } \\
\text { tional study }\end{array}$ & $\begin{array}{l}25 \text { female adoles- } \\
\text { cent/15.3 } \pm 1.1 \\
\text { years }\end{array}$ & $\begin{array}{l}\text { A: weight training, } \\
\text { B: swimming, } \\
\text { C: non-athletes }\end{array}$ & $\begin{array}{l}\text { B: } 15.7 \pm 4.5 \mathrm{hr} / \text { week, } 6 \text { day/week for } \\
6.5 \pm 2.6 \text { year; C: } 19.6 \pm 2.3 \mathrm{hr} / \text { week } \\
6 \text { day/week for } 2.6 \pm 1.6 \text { year }\end{array}$ & WB BMD: A>B, C \\
\hline Stear et al.[53] & INT & $\begin{array}{l}144 \text { girls } / 17.3 \pm \\
0.3 \text { years }\end{array}$ & $\begin{array}{c}\text { A: Ca+EX, B: Ca+no EX, } \\
\text { C: placebo+EX, D: placebo+ } \\
\text { no EX, EX: weight-bearing, } \\
\text { moderate-to-high impact } \\
\text { movements }\end{array}$ & $\begin{array}{l}\text { Total } 15.5 \text { months; } 30 \text { min/day, } 3 \text { times/ } \\
\text { week for moderate-to-vigorous intensity }\end{array}$ & WB BMC: $A>D$ \\
\hline
\end{tabular}

FITT, frequency, intensity, time, and type; INT, intervention; AT, aerobic training; RT, resistance training; Ca, calcium; EX, exercise; BMD, bone mineral density; BMC, bone mineral content; WB, whole body; FN, femoral neck; NS, non-significant; LS, lumbar spine.

incorrect lifting program design used for resistance exercise may cause physical injury,[46] and all precautions are warranted to avoid this complication. A well-designed resistance exercise program must emphasize education regarding proper lifting form, adequate supervision, and effectively scaled lifting.[56] A teacher trained in physical education can provide such education and management during class to implement this effective strategy aimed at improving PBM in this population. A resistance exercise program using weight-bearing PA that is relatively easier to learn and teach and does not require specialized equipment is preferred over training methods that require high levels of technical expertise, or the use of weight machines and equipment that is not easily available, and/or methods that involve relatively difficult postures. Jumping effectively improves the bone mass in adolescents.[6,53,5759] A resistance exercise program utilizing this simple activity can serve as an effective strategy to improve the PBM in adolescents, primarily because this activity is easy to teach and incorporate into class activity.

\section{KQ8: Is impact exercise effective for improving BMD in adolescence?}

Impact exercise refers to the exercise that produces fast and powerful movements using the extension and shortening cycles of the muscle with explosive concentric muscle contraction induced following an eccentric muscle action. Plyometric exercise is a form of high-intensity exercise mainly used by elite athletes to enhance agility, flexibility, or muscle strength in general. Various types of low-intensity jumping exercises such as jumping on both feet and jumping rope have been reported to increase muscle strength in adolescents, particularly in the lower extremities, and help in maintaining proper weight.[60-65] Additionally, recent studies have reported that impact exercise is one of the key exercise strategies for improving BMD and PBM in 


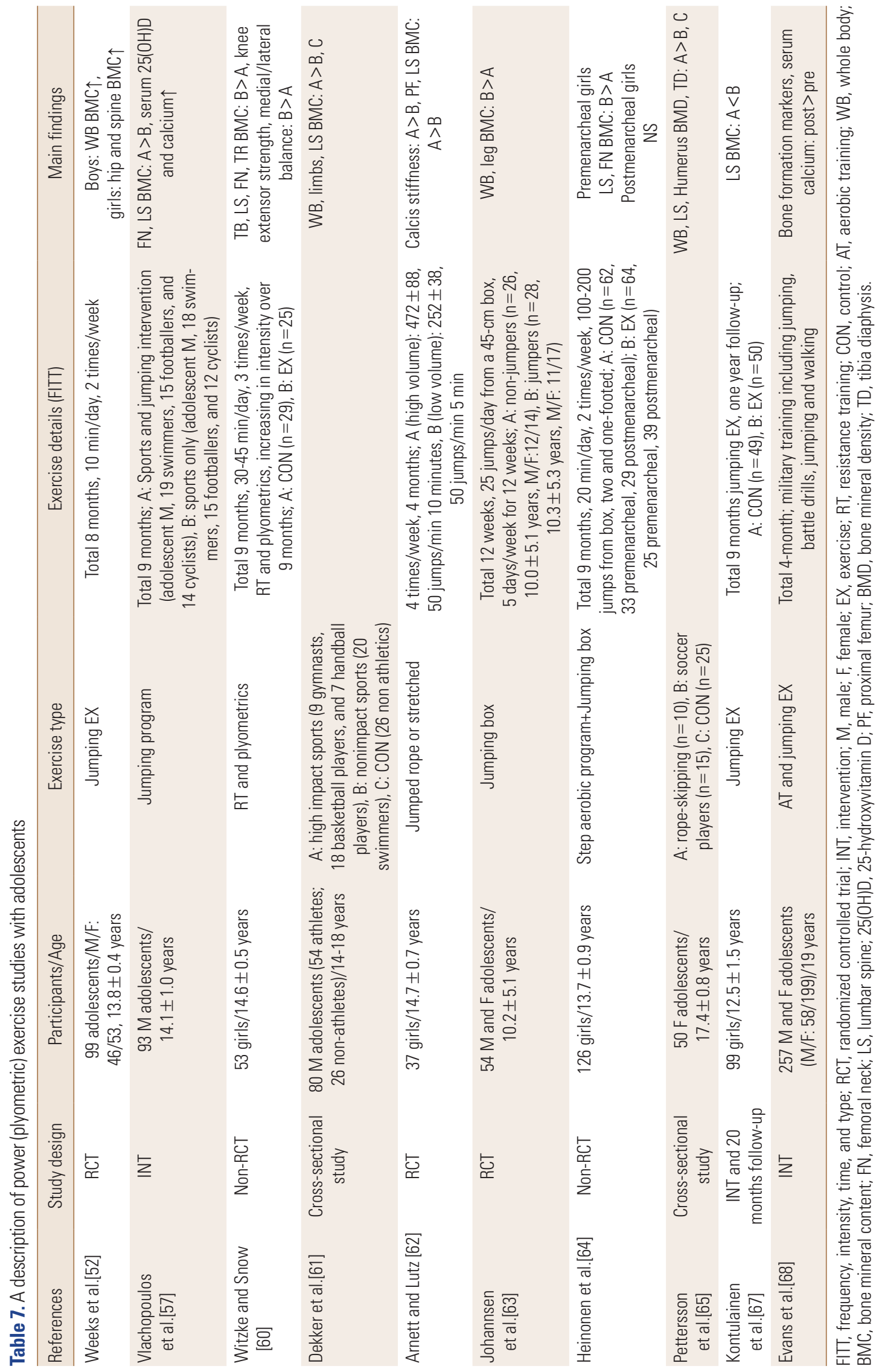


adolescents.[60] According to a study by Weeks et al.[52] an 8-month intervention involving 10 min of jumping exercises before starting regular class twice a week led to a higher pelvic and lumbar BMD in female adolescents than in the controls, and the study by Witzke and Snow [60] showed that a 9-month intervention of resistance and plyometric exercises for 30 to $45 \mathrm{~min}$ a day 3 times a week increased systemic, lumbar, and femoral BMD. Athletes who performed high-impact sports had higher overall body or lumbar BMD than athletes who engaged in sports receiving less impact from the ground, such as cycling or swimming.[66] Additionally, it was shown that female students undergoing a 9-month intervention with jumping exercises had higher lumbar BMD compared to the group who did not perform the exercise, and the increase in lumbar BMD was maintained in a follow-up test performed 20 months later.[67] Thus, the results of the previous studies suggest that plyometric or jumping exercise is an important form of exercise for improving adolescent BMD and that BMD increase in childhood or adolescence through plyometric exercise can prevent musculoskeletal diseases such as osteoporosis in adulthood.

\section{KQ9: How can impact exercises be applied to} be effective in increasing PBM in adolescents?

To date, an accurate FITT on the strategy for prescribing plyometric exercise to increase BMD in adolescents has not been presented, but the summary of previous studies is shown in Table 7. The intervention with jumping exercises was attempted in adolescents with varying duration between 16 weeks and 2 years. When 16 weeks of aerobic endurance exercise was combined with jumping exercise, we confirmed that the level of biomarkers related to osteo- genesis was increased in the blood and believe that the intervention of jumping exercises for at least 16 weeks is sufficient to induce a change in BMD.[68] Moreover, it was shown that the BMD in male and female adolescents increased when approximately 10 min of jumping exercise was performed twice a week for 8 months before starting regular class, and combining aerobic or resistance exercise with jumping exercise also increased BMD in the lower limbs when they were performed for 45 min a day 3 times a week for at least 9 months. $[52,60]$ In other words, jumping exercises such as box jump or jumping rope performed for approximately $10 \mathrm{~min}$ at least twice a week for approximately 9 months is considered sufficient to increase BMD. However, due to the risk of injury when performing jumping exercises using a high box, adolescents are recommended to choose lower-intensity exercises such as jumping rope, jumping, and hopping.

\section{DISCUSSION}

The purpose of establishing these exercise guidelines is to provide evidence-based exercise method to improve PBM in adolescents. Through this, it will be possible to contribute to public health by reducing the incidence of osteoporosis and fractures in the aging society in the future. The key significance of these guidelines is to understand the methods and effects of various exercises that affect the increase in BMD in adolescents and instruct them accordingly by controlling the FITT of exercises. To establish these guidelines, a joint exercise committee was formed by the KSBMR and KSEP. This committee determined the effects of exercise based on the criteria of level of evidence and the grade of recommendation through systematic litera-

Table 8. Exercise guidelines based on frequency, intensity, time, and type for increasing peak bone mass in adolescents

\begin{tabular}{|c|c|c|c|c|c|c|}
\hline Modality & Frequency & Intensity & Time & Type & Evidence $^{\mathrm{a})}$ & Grade $^{\text {bl }}$ \\
\hline Physical activity & $\geq 2-5$ days $\cdot W^{-1}$ & $\begin{array}{l}\text { Dependent on each } \\
\text { exercise method }\end{array}$ & $\begin{array}{l}\text { Dependent on each } \\
\text { exercise method }\end{array}$ & $\begin{array}{l}\text { Vigorous physical activity including resis- } \\
\text { tance and impact exercise } \geq 5-6 \text { months }\end{array}$ & I & A \\
\hline Resistance exercise & 3 days. $\mathrm{W}^{-1}$ & 10-12 rep. $\cdot$ set $^{-1}$ & $1-2$ set.region ${ }^{-1}$ & $\begin{array}{c}\text { Resistance exercise by combination of } \\
\text { free weight and machines including } \geq 8 \\
\text { large muscles }\end{array}$ & I & A \\
\hline Impact exercise & $\geq 2$ days $\cdot W^{-1}$ & $\geq 50$ jumps $\cdot \mathrm{min}^{-1}$ & $\geq 10$ min $\cdot$ day $^{-1}$ & $\begin{array}{l}\text { Impact exercise by plyometrics, jumping, } \\
\text { rope-skipping, etc. }\end{array}$ & I & A \\
\hline Aerobic exercise & $\geq 3-5$ days $\cdot W^{-1}$ & RPE 11-15 & $\geq 60$ min $\cdot$ day $^{-1}$ & $\begin{array}{l}\text { Weight-bearing aerobic exercise by } \\
\text { jogging, running, etc. }\end{array}$ & $\|$ & B \\
\hline
\end{tabular}

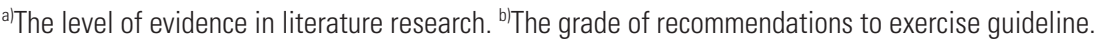

RPE, rating of perceived exertion. 
ture review and established exercise guidelines by selecting effective exercise methods. The exercise guidelines for improving PBM in adolescents included in the final selection are presented in Table 8 . These guidelines recommend VPA of at least 5 to 6 months, and it is recommended that VPA includes resistance exercise and impact exercise. Resistance exercise is a form of exercise combining free weight and machines exercise, and the recommendation is that this is performed using at least 8 large muscles with 10 to 12 times in a set for 1 to 2 sets a region, 3 days a week. The recommendation for impact exercise is performing exercises such as plyometrics, jumping, and skipping rope 50 jumps a min, at least 10 min a day, twice a week (Fig. 2). However, negative effects of aerobic exercises such as swimming and endurance running on the improvement of BMD have been reported by some studies, and this exercise is selectively recommended as the results presented may change with confirmatory study and the evidence is insufficient.

Recently, various exercise guidelines for maintaining and promoting bone health have been proposed in various countries. The position statement on exercise prescription for the prevention and management of osteoporosis published by the Exercise and Sports Science Australia divided the subjects into low, moderate, and high-risk individuals and presented the methods for impact loading, progressive resistance training, and balance training.[17] Furthermore, in a guideline published by a team of multinational researchers,[16] multicomponent exercise program including resis- tance and balance training is recommended for elderly adults with osteoporosis and osteoporotic vertebral fracture. These papers provide exercise guidelines for adults who wish to prevent osteoporosis or for patients with osteoporosis and cannot be generalized to adolescents in puberty. In the $P A$ Guidelines for Americans [19] recently published by the USDHHS, PA guidelines for various age groups were published that recommended $60 \mathrm{~min}(1 \mathrm{hr}$ ) or more of moderate-to-VPA daily for children and adolescents aged 6 to 17 years. Specifically, it is worth noting that the recommendation states that bone-strengthening PA of $60 \mathrm{~min}$ or more daily on at least 3 days a week must be included. However, these guidelines are focused on national health and cannot be regarded as research results specific to exercise and BMD. Additionally, there is no distinction between children and adolescents, and a specific method of exercise outlining the FITT is not presented. Compared to these guidelines, our exercise guidelines for improving PBM in adolescence have summarized the results after a comprehensive review of various exercise methods that affect the increase in BMD and presented the exercise guidelines specific to the age group of 13 to 18 years old.

Meanwhile, according to the "2018 Statistical Analysis of Student Health Examination Sample" by the Ministry of Education, while the general physique was improved with increasing body weight and height in male and female middle/high school students, the proportion of students who perform VPA at least 3 times a week was low with

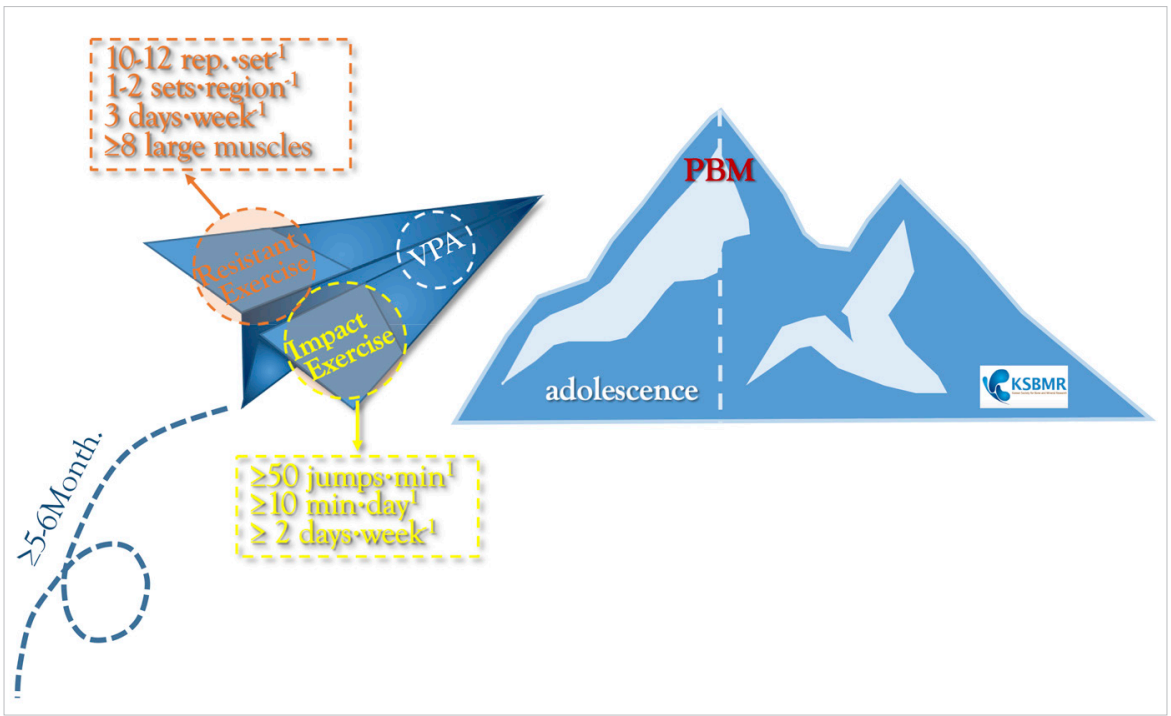

Fig. 2. Exercise guidelines for increasing peak bone mass (PBM) in adolescence. VPA, vigorous physical activity. 
$35.08 \%$ and $23.60 \%$ in middle school and high school students, respectively, and the proportion of students who exercise more than 5 days a week was even lower with $14.59 \%$ and $9.69 \%$, respectively.[69] In addition to this, the level of physical strength including muscle strength, endurance, and agility in Korean adolescents has consistently decreased in the past decade according to a report.[70] Globally, the physical strength in adolescents is decreasing as well with reports indicating that $81 \%$ of adolescents aged 11 to 17 years do not engage in PA of at least $1 \mathrm{hr}$ a day.[71] Furthermore, the percentage of class time on physical education and health in Korean middle and high school students is approximately $8 \%$, which is slightly higher than the Organisation for Economic Co-operation and Development's average of 7\%, but it is still lower than that of Japan, Canada, and France, which is approximately 10\%.[72] Additionally, in a survey examining the actual time spent on performing exercise during physical education class at school, an average of $43.0 \%$ of middle and high school students responded that they engaged in "less than $1 \mathrm{hr}$ per week of exercise that made them sweat" at school, and participation in sports was significantly lower in female students compared to male students.[73] A detailed research was probably not conducted, but it is believed that participation of adolescents in sports is at a seriously low level considering that these few hours of physical education is usually replaced by other subjects such as English and Mathematics for the 2nd and 3rd year high school students who are preparing for university entrance examination. As shown, adolescents in Korea show a very low participation level in physical activities, and the overall physical fitness is decreasing as they are not getting sufficient exercise during physical education class $\mathrm{hr}$ at school, which is far more insufficient compared to that of other developed countries.

This study has shown that VPA, including resistance exercise and impact exercise, improves PBM by increasing $B M D$ in adolescents. Therefore, efforts to actively implement VPA presented in exercise guidelines will be needed. To achieve this, it is necessary to promote physical education at schools and systematically apply the exercises presented in these guidelines. Additionally, if BMD is included in the Statistical Analysis of Student Health Examination Sample conducted by the Ministry of Education annually and is managed with obesity, it will be easier for students to engage in VPA, and this could significantly contribute to the promotion of national health in Korea.

When establishing these exercise guidelines, we planned the review based on the results of the research in Asian adolescents including adolescents in Korea to account for racial differences. However, because of insufficient papers, there is a limitation in restricting the subjects to Korean adolescents as there were multiple ethnicities from the USA and Europe in the subject population. Moreover, other limitations include the fact that papers that take calcium intake into account are mixed with those that did not and that BMD evaluations were conducted using different types of equipment.

The KSBMR and KSEP recommend the following as an exercise method for improving PBM in adolescents: at least 5 to 6 months of VPA, which includes both resistance and impact exercises. It is recommended that resistance exercise is performed using at least 8 large muscles with 10 to 12 times in a set for 1 to 2 sets a region, 3 days a week. For impact exercises such as jumping, it is recommended that the exercise is performed 50 jumps a min, at least $10 \mathrm{~min}$ a day, twice a week.

\section{DECLARATIONS}

\section{Ethics approval and consent to participate} Not applicable.

\section{Conflict of interest}

No potential conflict of interest relevant to this article was reported.

\section{ORCID}

Seok-Ki Min https://orcid.org/0000-0003-3134-9689

Taewoong Oh https://orcid.org/0000-0003-0533-4539

Sang-Hyun Kim https://orcid.org/0000-0001-9657-4575 Jinkyung Cho https://orcid.org/0000-0002-4500-3622 Ho-Yeon Chung https://orcid.org/0000-0002-4529-8280 Dong-Ho Park https://orcid.org/0000-0003-1863-0652 Chang-Sun Kim https://orcid.org/0000-0003-4317-3609

\section{REFERENCES}

1. Duncan CS, Blimkie CJ, Cowell CT, et al. Bone mineral density in adolescent female athletes: relationship to exercise 
type and muscle strength. Med Sci Sports Exerc 2002;34: 286-94.

2. LeBlanc AD, Spector ER, Evans HJ, et al. Skeletal responses to space flight and the bed rest analog: a review. J Musculoskelet Neuronal Interact 2007;7:33-47.

3. Warden SJ, Hurst JA, Sanders MS, et al. Bone adaptation to a mechanical loading program significantly increases skeletal fatigue resistance. J Bone Miner Res 2005;20:80916.

4. Krahl H, Michaelis U, Pieper HG, et al. Stimulation of bone growth through sports. A radiologic investigation of the upper extremities in professional tennis players. Am J Sports Med 1994;22:751-7.

5. Office of the Surgeon General. Bone health and osteoporosis: A report of the surgeon general. Rockville, MD: Office of the Surgeon General; 2004.

6. Kohrt WM, Bloomfield SA, Little KD, et al. American college of sports medicine position stand: physical activity and bone health. Med Sci Sports Exerc 2004;36:1985-96.

7. Heaney RP, Abrams S, Dawson-Hughes B, et al. Peak bone mass. Osteoporos Int 2000;11:985-1009.

8. Hernandez CJ, Beaupré GS, Carter DR. A theoretical analysis of the relative influences of peak BMD, age-related bone loss and menopause on the development of osteoporosis. Osteoporos Int 2003; 14:843-7.

9. Clark EM, Ness AR, Bishop NJ, et al. Association between bone mass and fractures in children: a prospective cohort study. J Bone Miner Res 2006;21:1489-95.

10. Baptista F, Janz KF. Habitual physical activity and bone growth and development in children and adolescents: $A$ public health perspective. In: Preedy VR, editor. Handbook of growth and growth monitoring in health and disease. New York, NY: Springer; 2011. p.2395-411.

11. Gunter KB, Almstedt HC, Janz KF. Physical activity in childhood may be the key to optimizing lifespan skeletal health. Exerc Sport Sci Rev 2012;40:13-21.

12. Troiano RP, Berrigan D, Dodd KW, et al. Physical activity in the United States measured by accelerometer. Med Sci Sports Exerc 2008;40:181-8.

13. Ministry of Education, Ministry of Health and Welfare, Korea Centers for Disease Control and Prevention. The twelfth Korea youth risk behavior web-based survey. Sejong: Ministry of Education, Ministry of Health and Welfare, Korea Centers for Disease Control and Prevention; 2016.

14. National Youth Policy Institute. Study on the current sta- tus of Korean children's and youth rights III. Sejong: National Youth Policy Institute; 2013.

15. Kim SY, Ji SM, Lee SJ, et al. Guidance for development of clinical practice guidelines. Seoul: National Evidence-based Healthcare Collaborating Agency; 2011.

16. Giangregorio LM, Papaioannou A, Macintyre NJ, et al. Too Fit To Fracture: exercise recommendations for individuals with osteoporosis or osteoporotic vertebral fracture. Osteoporos Int 2014;25:821-35.

17. Beck BR, Daly RM, Singh MA, et al. Exercise and sports science Australia (ESSA) position statement on exercise prescription for the prevention and management of osteoporosis. J Sci Med Sport 2017;20:438-45.

18. Janz KF, Thomas DQ, Ford MA, et al. Top 10 research questions related to physical activity and bone health in children and adolescents. Res Q Exerc Sport 2015;86:5-12.

19. U.S. Department of Health and Human Services. Physical activity guidelines for Americans. 2nd ed. Washington, DC: U.S. Department of Health and Human Services; 2018.

20. Higgins JPT, Green S, editors. Cochrane handbook for systematic reviews of interventions: Version 5.1.0. London, UK: The Cochrane Collaboration; 2011.

21. Bailey DA, McKay HA, Mirwald RL, et al. A six-year longitudinal study of the relationship of physical activity to bone mineral accrual in growing children: the university of Saskatchewan bone mineral accrual study. J Bone Miner Res 1999;14:1672-9.

22. Baxter-Jones AD, Faulkner RA, Forwood MR, et al. Bone mineral accrual from 8 to 30 years of age: an estimation of peak bone mass. J Bone Miner Res 2011;26:1729-39.

23. Berger C, Goltzman D, Langsetmo L, et al. Peak bone mass from longitudinal data: implications for the prevalence, pathophysiology, and diagnosis of osteoporosis. J Bone Miner Res 2010;25:1948-57.

24. Weaver CM, Gordon CM, Janz KF, et al. Erratum to: The National Osteoporosis Foundation's position statement on peak bone mass development and lifestyle factors: a systematic review and implementation recommendations. Osteoporos Int 2016;27:1387.

25. Tveit $M$, Rosengren BE, Nilsson JÅ, et al. Exercise in youth: High bone mass, large bone size, and low fracture risk in old age. Scand J Med Sci Sports 2015;25:453-61.

26. Strope MA, Nigh P, Carter Ml, et al. Physical activity-associated bone loading during adolescence and young adulthood is positively associated with adult bone mineral den- 
sity in men. Am J Mens Health 2015;9:442-50.

27. Bielemann RM, Domingues MR, Horta BL, et al. Physical activity throughout adolescence and bone mineral density in early adulthood: the 1993 Pelotas (Brazil) Birth Cohort Study. Osteoporos Int 2014;25:2007-15.

28. Tolonen S, Sievanen H, Mikkilä V, et al. Adolescence physical activity is associated with higher tibial pQCT bone values in adulthood after 28-years of follow-up--the Cardiovascular Risk in Young Finns Study. Bone 2015;75:77-83.

29. Jackowski SA, Kontulainen SA, Cooper DM, et al. Adolescent physical activity and bone strength at the proximal femur in adulthood. Med Sci Sports Exerc 2014;46:736-44.

30. Ramires VV, Dumith SC, Wehrmeister FC, et al. Physical activity throughout adolescence and body composition at 18 years: 1993 Pelotas (Brazil) birth cohort study. Int J Behav Nutr Phys Act 2016;13:105.

31. Duckham RL, Baxter-Jones AD, Johnston JD, et al. Does physical activity in adolescence have site-specific and sexspecific benefits on young adult bone size, content, and estimated strength? J Bone Miner Res 2014;29:479-86.

32. Marin-Puyalto J, Mäestu J, Gómez-Cabello A, et al. Frequency and duration of vigorous physical activity bouts are associated with adolescent boys' bone mineral status: A cross-sectional study. Bone 2019;120:141-7.

33. Nordström P, Pettersson U, Lorentzon R. Type of physical activity, muscle strength, and pubertal stage as determinants of bone mineral density and bone area in adolescent boys. J Bone Miner Res 1998;13:1141-8.

34. Diniz TA, Agostinete RR, Costa PJ, et al. Relationship between total and segmental bone mineral density and different domains of physical activity among children and adolescents: cross-sectional study. Sao Paulo Med J 2017; 135:444-9.

35. Eliakim A, Raisz LG, Brasel JA, et al. Evidence for increased bone formation following a brief endurance-type training intervention in adolescent males. J Bone Miner Res 1997; 12:1708-13.

36. Im KC. Effects of athletics exercise program on the healthrelated fitness, abdominal fat area and bone mineral density in middle school girls. Korea J Sports Sci 2016;25:133746.

37. Okano $H$, Mizunuma $H$, Soda $M$, et al. Effects of exercise and amenorrhea on bone mineral density in teenage runners. Endocr J 1995;42:271-6.

38. Jang JH. Comparison of upper limb bone density between high school women soccer players and age-matched women students. Korea J Sport 2008;6:167-75.

39. Burrows M, Nevill AM, Bird S, et al. Physiological factors associated with low bone mineral density in female endurance runners. Br J Sports Med 2003;37:67-71.

40. Nguyen T, Sambrook P, Kelly P, et al. Prediction of osteoporotic fractures by postural instability and bone density. BMJ 1993;307:1111-5.

41. Choi HG, Lee CD, Kang HY, et al. Bone mineral density in different types of sports: Female high school athletes. J Korean Phys Educ Assoc Girls Women 2006;20:37-44.

42. Agostinete RR, Maillane-Vanegas S, Lynch KR, et al. The impact of training load on bone mineral density of adolescent swimmers: A structural equation modeling approach. Pediatr Exerc Sci 2017;29:520-8.

43. Bellew JW, Gehrig L. A comparison of bone mineral density in adolescent female swimmers, soccer players, and weight lifters. Pediatr Phys Ther 2006;18:19-22.

44. Campos RM, de Mello MT, Tock L, et al. Aerobic plus resistance training improves bone metabolism and inflammation in adolescents who are obese. J Strength Cond Res 2014;28:758-66.

45. Snow-Harter C, Bouxsein ML, Lewis BT, et al. Effects of resistance and endurance exercise on bone mineral status of young women: a randomized exercise intervention trial. J Bone Miner Res 1992;7:761-9.

46. Faigenbaum AD, Kraemer WJ, Blimkie CJ, et al. Youth resistance training: updated position statement paper from the national strength and conditioning association. J Strength Cond Res 2009;23:560-79.

47. United States Consumer Product Safety Commission. National electronic injury surveillance system. Washington, DC: United States Consumer Product Safety Commission; 1987.

48. Volek JS, Gómez AL, Scheett TP, et al. Increasing fluid milk favorably affects bone mineral density responses to resistance training in adolescent boys. J Am Diet Assoc 2003; 103:1353-6.

49. Nichols DL, Sanborn CF, Love AM. Resistance training and bone mineral density in adolescent females. J Pediatr 2001; 139:494-500.

50. Bernardoni B, Thein-Nissenbaum J, Fast J, et al. A schoolbased resistance intervention improves skeletal growth in adolescent females. Osteoporos Int 2014;25:1025-32.

51. Koşar ŞN. Associations of lean and fat mass measures with 
whole body bone mineral content and bone mineral density in female adolescent weightlifters and swimmers. Turk J Pediatr 2016;58:79-85.

52. Weeks BK, Young CM, Beck BR. Eight months of regular inschool jumping improves indices of bone strength in adolescent boys and girls: the POWER PE study. J Bone Miner Res 2008;23:1002-11.

53. Stear SJ, Prentice A, Jones SC, et al. Effect of a calcium and exercise intervention on the bone mineral status of 16-18 y-old adolescent girls. Am J Clin Nutr 2003;77:985-92.

54. Welten DC, Kemper HC, Post GB, et al. Weight-bearing activity during youth is a more important factor for peak bone mass than calcium intake. J Bone Miner Res 1994;9: 1089-96.

55. Myers AM, Beam NW, Fakhoury JD. Resistance training for children and adolescents. Transl Pediatr 2017;6:137-43.

56. Vlachopoulos D, Barker AR, Ubago-Guisado E, et al. The effect of a high-impact jumping intervention on bone mass, bone stiffness and fitness parameters in adolescent athletes. Arch Osteoporos 2018;13:128.

57. Vlachopoulos D, Barker AR, Ubago-Guisado E, et al. A 9month jumping intervention to improve bone geometry in adolescent male athletes. Med Sci Sports Exerc 2018; 50:2544-54.

58. MacKelvie KJ, McKay HA, Petit MA, et al. Bone mineral response to a 7-month randomized controlled, school-based jumping intervention in 121 prepubertal boys: associations with ethnicity and body mass index. J Bone Miner Res 2002;17:834-44.

59. Larsen MN, Nielsen CM, Helge EW, et al. Positive effects on bone mineralisation and muscular fitness after 10 months of intense school-based physical training for children aged 8-10 years: the FIT FIRST randomised controlled trial. Br J Sports Med 2018;52:254-60.

60. Witzke KA, Snow CM. Effects of plyometric jump training on bone mass in adolescent girls. Med Sci Sports Exerc 2000;32:1051-7.

61. Dekker J, Nelson K, Kurgan N, et al. Wnt signaling-related osteokines and transforming growth factors before and after a single bout of plyometric exercise in child and adolescent females. Pediatr Exerc Sci 2017;29:504-12.
62. Arnett MG, Lutz B. Effects of rope-jump training on the os calcis stiffness index of postpubescent girls. Med Sci Sports Exerc 2002;34:1913-9.

63. Johannsen N, Binkley T, Englert V, et al. Bone response to jumping is site-specific in children: a randomized trial. Bone 2003;33:533-9.

64. Heinonen A, Sievanen H, Kannus P, et al. High-impact exercise and bones of growing girls: a 9-month controlled trial. Osteoporos Int 2000;11:1010-7.

65. Pettersson U, Nordström $P$, Alfredson $\mathrm{H}$, et al. Effect of high impact activity on bone mass and size in adolescent females: A comparative study between two different types of sports. Calcif Tissue Int 2000;67:207-14.

66. Dias Quiterio AL, Carnero EA, Baptista FM, et al. Skeletal mass in adolescent male athletes and nonathletes: relationships with high-impact sports. J Strength Cond Res 2011;25:3439-47.

67. Kontulainen SA, Kannus PA, Pasanen ME, et al. Does previous participation in high-impact training result in residual bone gain in growing girls? One year follow-up of a 9-month jumping intervention. Int J Sports Med 2002;23:575-81.

68. Evans RK, Antczak AJ, Lester M, et al. Effects of a 4-month recruit training program on markers of bone metabolism. Med Sci Sports Exerc 2008;40:S660-70.

69. Ministry of Education. Sampling design of student health examinations in 2018. 2019 [cited by 2019 May 1]. Available from: https://www.moe.go.kr/boardCnts/view.do?bo $\operatorname{ardID}=294 \&$ boardSeq $=77144 \& \mathrm{lev}=0 \& \mathrm{~m}=02$

70. Ministry of Culture, Sports and Tourism. Survey on citizens' sports participation. Seoul: Ministry of Culture, Sports and Tourism; 2015.

71. World Health Organization. Prevalence of insufficient physical activity. Geneva, CH: World Health Organization; 2010.

72. Organisation for Economic Co-operation and Development. Education at a glance 2015: OECD indicators. Paris, FR: OECD Publishing; 2015.

73. National Youth Policy Institure. NYPI panel survey: Junior high school. 2010 [cited by 2011 Aug 1]. Available from: https://www.nypi.re.kr/archive/brdartcl/boardarticleList. do?brd_id=BDIDX_3A94C7B4Y1bY00jGQSP1xB\&menu_ nix $=$ tli305c4\&srch_mu_lang =ENG 
